\title{
Design and Evaluation of an Adaptive Empathy Learning Tool
}

\author{
Thiemo Wambsganss \\ University of St.Gallen, St.Gallen, \\ Switzerland \\ thiemo.wambsganss@unsig.ch
}

\author{
Florian Weber \\ University of Kassel, Kassel, \\ Germany \\ weber@uni-kassel.de
}

\author{
Matthias Söllner \\ University of Kassel, Kassel, \\ Germany \\ soellner@uni-kassel.de
}

\begin{abstract}
Empathy is an elementary skill for daily interactions and for professional communication, agile teamwork and successful leadership and thus elementary for educational curricula. However, educational organizations face difficulties in providing the boundary conditions necessary for their students to develop empathy skills due to the lack of individual support in traditional large-scale and growing distance-learning scenarios. Drawing on cognitive dissonance theory, we propose an adaptive empathy learning tool that helps students develop their ability to react to other people's observed experiences through individual feedback in large-scale or distance learning scenarios. Based on a design science research project, we propose a set of design principles and instantiate and evaluate them with our prototype Eva in an online experiment with 65 students. The findings suggest that an adaptive empathy learning tool that follows our design principles is a promising approach to individually support students in their ability to react to other people's observed abilities in traditional learning scenarios.
\end{abstract}

\section{Introduction}

Empathy is not only an elementary skill for our society but also for professional communication, agile teamwork and successful leadership and thus elementary for educational curricula (i.e., OECD Learning Framework 2030) [1]. Empathy ${ }^{1}$ is defined as the "ability to simply understand the other person's perspective [...] and to react to the observed experiences of another" (Davis [2], p. 1). Empathy skills not only pave the foundation for successful interaction in digital companies, e.g., in agile work environments [3], but they are also one of the key abilities in the future that distinguish human work force from artificial intelligence agents [4]. However, besides the growing importance of empathy, research has shown that empathy skills of US college students have decreased from 1979 to 2009 by more than thirty percent and even more rapidly from
2000 to 2009 [5]. On these grounds, the Organization for Economic Cooperation and Development (OECD) claims that training empathy skills should receive a more prominent role in today's higher education [1]. To train empathy in students, educational institutions traditionally rely on experiential learning scenarios, such as shadowing, communication skills training or role-playing, e.g., in medical education [6]. Individual empathy training is therefore only available for a limited number of students, since individual tutoring throughout a student's learning journey is often hindered due to traditional large-scale lectures or the growing field of distance learning scenarios such as Massive Open Online Courses (MOOCs, [7]). However, to develop skills such as empathy, it is of utmost importance for the individual student to receive continuous feedback throughout his or her learning journey [8], [9]. In fact, educational institutions are limited in providing these individual learning conditions especially for empathy skill training in a traditional way.

A promising way to support students to train the ability to react to other people's observed experiences [2] and enable teachers to convey it to classes of large sizes and independent from location is the usage of adaptive technology-based applications in a pedagogical scenario for a student's learning journey. Researchers especially from the field of Educational Technology have designed pedagogical scenarios to train the empathy skills of students through virtual reality role-playing for social work education [10], virtual agents to simulate patient treatments for nurses (e.g., [6]) or adaptive empathy text feedback on computer-mediated communication platforms to foster empathy for company-client and employee-customer relationships [11]. However, novel technologyenhanced pedagogical scenarios based on recent advances in Natural Language Processing (NLP) or Machine Learning (ML) that allow new forms of human-computer interaction to support learners in

\footnotetext{
${ }^{1}$ Being aware that empathy is a multidimensional construct, in this study we focus on emotional and cognitive empathy by [2], [21].
} 
learning empathetic interaction through adaptive tutoring fall rather short in literature. A possibility to provide adaptive empathy feedback on natural language is the field of empathy detection form Computational Linguistics [12]. Empathy detection has been a growing research approach to identify and model empathetic structures and phrases of a given text in real time, which could be leveraged to provide students with individual feedback, e.g., on peer reviews on business models or team conversation logs [11], [12]. However, despite the vast amount of studies, current literature falls short of providing an approach with principles and proof on how to design an adaptive and intelligent learning tool that helps students to learn how to react to other students' perspectives with intelligent feedback. Thus, we aim to contribute to the field of technology-enhanced empathy learning by answering the following research question (RQ):

RQ: How should an adaptive learning tool that helps students to train their empathy skill be designed in largescale or distance learning scenarios?

To contribute to our research question, we follow the design science research approach (DSR) by Peffers et al. [13]. As stated above, there is a lack of design knowledge for technology-enhanced tools to convey empathy skills. We aim to iteratively design and evaluate an IT learning artifact on the baseline of existing theory (cognitive dissonance based on Festinger [14]) informing the artifact design [15], [16]. We believe cognitive dissonance theory could explain why formative feedback on a student's empathy skills will motivate the student to be more aware and sensitive towards empathetic behavior. To the best of our knowledge, there is no study that rigorously derives requirements from both scientific literature and potential users to develop an adaptive IT learning tool for helping IS students learn how to react to other students' perspectives based on this theoretical lens. By adaptive learning tool, we understand a tool that provides individual and real-time feedback on the emotional and cognitive empathy level to students on a given text, e.g., a chat conversation, and provides suggestions on how to write more empathetically, e.g., when writing peer reviews on business ideas. Based on DSR, we first define the problem and gather requirements from practice and literature. Second, we propose design principles and instantiate and evaluate them through our learning tool Eva in an online experiment with 65 students. The results indicate that our derived design principles lead to a higher perceived level of enjoyment and students would intend to use the tool to train the empathy skills if it was available.

The remainder of our paper is structured as follows: first, we describe the necessary theoretical background on empathy learning. In section 3 , we explain how we proceed to develop a first prototype of our empathy learning tool based on derived design principles. In section 4, we conduct an online experiment to get first insights into the usefulness of the tool. Finally, we close with a discussion, limitations and the contributions of our study.

\section{Theoretical Background}

\subsection{Empathy Learning}

The ability to perceive the feelings of another person and to react to their emotions in the right way requires empathy. Empathy plays an essential role in daily life in many practical situations, such as client communication, leadership or agile teamwork. Therefore, especially business schools today are increasingly trying to focus on fostering empathy skills [17] to provide students with the right skill set to meet future job profiles (i.e., [18]). The importance of empathy and other metacognition skills has been manifested by the $O E C D$, which included them as a major element of their Learning Framework 2030 [1]. Despite the interdisciplinary research interest, the term empathy is defined from multiple perspectives in terms of its dimensions or components [19]. Being aware that there are multiple perspectives on empathy, in this paper we focus on the cognitive and emotional components of empathy as defined by [9] and 19]. Therefore, we follow the Toronto Empathy Scale [21] as a synthesis of instruments for measuring and validating empathy. Empathy refers to the "ability to simply understand the other person's perspective [...] and to react to the observed experiences of another" ([2], p. 1), where empathy consists of both emotional and cognitive components [21]. While emotional empathy lets us perceive what other people feel, cognitive empathy is the human ability to recognize and understand other individuals [20]. Besides the importance of empathy in daily life, studies have shown that empathy skills of US college students have decreased from 1979 to 2009 by more than thirty percent and even more rapidly in the last period from 2000 to 2009 [5]. Possible explanations are given by the growing amount of digital communication in our society [5]. Scientists therefore urge that training empathy skills should receive a more prominent role in today's higher education (e.g., [1], [10]). In fact, individual support of empathy learning is missing in most learning scenarios. In some domains training programs are designed to increase empathy skills through role plays, films, literature or video games (e.g., [22]). Since social professions, in particular, are characterized by interactions, similar training programs that promote empathy or empathetic forms of expression have so far also been successfully implemented for social workers [23], doctors and 
nurses [24]. In business education, empathy is usually trained through communication scenarios, classroom exercises, role plays or experiential learning (e.g., [17]). In fact, empathy is often regarded as a subcomponent of social competence [25], and corresponding support measures often take place in extensive programs to promote social development. However, in order to train skills such as empathy, it is essential for the individual student to receive continuous feedback, also called formative feedback, throughout the learning process [8]. According to Sadler [26], the result of feedback is specific information about the learning task or process that fills a gap between what is understood and what should be understood. Even in areas where empathy is part of the curriculum, such as health or social work, the ability of a teacher to provide tutoring is naturally limited by time and availability constraints. Especially in more frequent large lectures and distance learning scenarios, the ability to individually support a student's empathy ability is hampered because it is becoming increasingly difficult for educators to provide continuous and individual feedback to a single student.

\subsection{Technology-Based Learning Systems for Empathy Skills}

Many researchers, especially from the fields of Educational Technology, have analyzed how technology-based systems in sociotechnical scenarios can enhance students' learning of empathy. The application of information technology in education bears several advantages, such as consistency, scalability, perceived fairness, widespread use and better availability compared to human teachers, and thus technologyenhanced empathy learning systems can help to relieve some of the burden on teachers to convey empathy by supporting learners with adaptive empathy feedback. Scientists have successfully embedded computerassisted instruction (CAI) in the form of virtual reality (VR) learning tools in pedagogical scenarios to enable students to directly dive into the perspective of, e.g., a client or a patient (e.g., [24]). Moreover, intelligent tutoring systems (ITS), in the form of virtual agents built into online tools, are used, e.g., to enable the interaction with emotional avatars (e.g., [27]). Lastly, computersupported collaborative learning (CSCL) tools are implemented to enhance empathy in the text communication of learners [11]. In their approach, Santos et al. use a simple library of messengers based on neurolinguistics, psychometrics and text mining techniques to promote empathy among students' interaction based on identification and text matching suggestions [11]. The combination of ITS and CSCL to design adaptive empathy learning tools is scarcely investigated in literature [11]. The aim is to provide pedagogical feedback on a learner's actions and solutions, hints and recommendations to encourage and guide future activities in the writing processes or automated evaluation to indicate whether a student's reaction to another person's perspective is emotionally appropriate. The design and implementation of ITS and CSCL to build adaptive learning tools is a rather complex endeavor that must rely on expertise from the fields of computer science (i.e., development of feedback algorithms), human-computer interaction (i.e., design of the interface) and educational technology (i.e., integration into the learning process). Therefore, we aim to address this research gap and rigorously design an empathy learning tool based on educational theory through the application of recent developments in NLP and ML (e.g., [28], [29]), in which empathy detection has been a growing research approach to identify and model empathetic structures of a given text in real time [11], [12]. The potential of empathy detection has been investigated in different domains but not leveraged for individual tutoring or feedback in a student's learning progress [12].

\subsection{Cognitive dissonance as a Kernel Theory for Individual Learning}

We believe that Cognitive Dissonance Theory supports our underlying hypothesis that individual and personal feedback on a student's ability to react to other people's perspectives in an emotionally appropriate manner motivates the student to improve their skill level [14]. Especially for students in a learning process, cognitive dissonance is a highly motivating factor to gain and acquire knowledge to actively resolve the dissonance [30]. It can be an initial trigger for a student's learning process and thus the construing of new knowledge structures [31]. However, the right portion of cognitive dissonance is very important for the motivation to solve it. According to Festinger, individuals might not be motivated enough to resolve it if the dissonance is too obvious, whereas a high level of dissonance might lead to frustration. Therefore, we believe that the right level of feedback on a student skill, such as empathy skills, could lead to cognitive dissonance and thus to motivation to change the behavior, belief or knowledge to learn how to react to other people's perspectives in an appropriate manner.

\section{Research Methodology}

Our study follows the DSR approach of Peffers et al. [13]. Figure 1 shows the research phases we conducted. The first phase of the DSR approach includes the problem formulation. We therefore described the relevance of the practical problem in the introduction of this work. For the objectives of $a$ solution phase, we derived a set of meta-requirements (MRs) from the current state of scientific literature for 


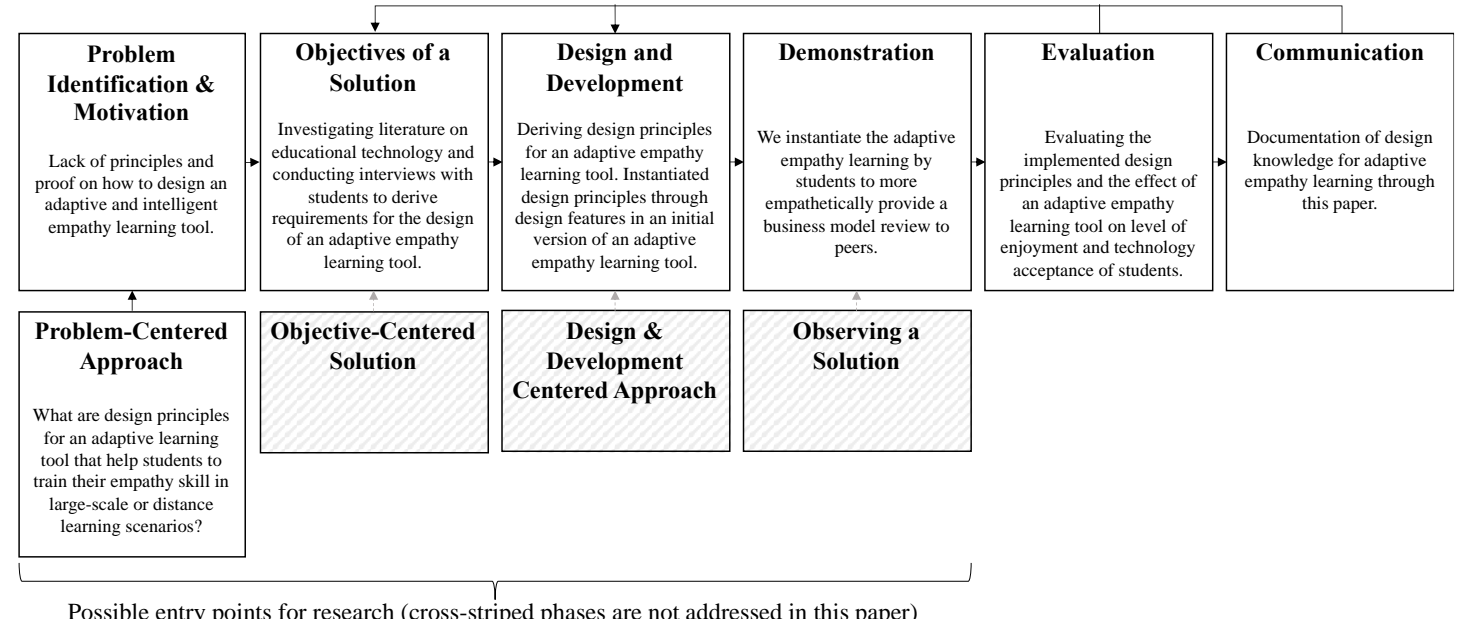

Possible entry points for research (cross-striped phases are not addressed in this paper)

Figure 1. Design science research approach adapted from Peffers et al. [13]

the design of an empathy learning tool. Based on those insights, we conducted 28 semi-structured interviews with master's students using the expert interview method by Gläser and Laudel [32]. We gathered user stories (USs) and user requirements (URs) for the design of an adaptive empathy learning tool based on those interviews [33]. In the third phase of the design science cycle (design and development), we derived five preliminary design principles (DPs) addressing the MRs and URs using the structure suggested by Gregor et al. [34] and designed an initial version as a first instantiation of these DPs. For the demonstration and the evaluation phase, we conducted a proof-of-concept evaluation based on evaluation criteria proposed by Venable et al. [35]. Based on the design principles, we created a mock-up prototype called Eva, where students were able to have a simple interaction with an adaptive empathy learning tool. We conducted an online experiment with 65 students to compare the concept of an adaptive empathy learning tool with a control group in which students conducted the exact same learning task but without using an adaptive learning tool based on our derived design principles following [36]. The goal of this evaluation was to see how students perceive the value of our instantiated design principles (e.g., by measuring the perceived level of enjoyment), to note change requests and to gather additional design principles. As a result of this evaluation, we refined our design knowledge based on the findings and added an additional sixth design principle for adaptive empathy learning tools. In the last phase (communication), we document the design knowledge with this paper.

\section{Design and Development}

In this part, we will describe and discuss how we gathered the requirements and derived the DPs. An overview of the practical and theoretical requirements as well as the derived DPs is shown in Figure 2.

\subsection{Deriving Requirements from Scientific Literature}

To derive requirements from scientific literature, a systematic literature search was conducted using the methodological approaches of Cooper [37] and vom Brocke et al. [38]. We initially focused our research on studies that demonstrate the successful implementation of learning tools for empathy skills. Two broad areas for deriving requirements were identified: educational technology and learning theories. Since the creation of a learning tool for empathy skills is a complex project that is studied by psychologists, pedagogues and computer scientists with different methods, we first concentrated on these literature streams. We only included literature that deals with or contributes to a kind of learning tool in the field of empathy learning, such as an established learning theory. On this basis, we selected 110 papers for more intensive analysis. We summarized similar topics of these contributions as literature issues (LIs) and formed five clusters

Individual formative feedback is essential for the learning of skills such as empathy (LI1, i.e., [8]). Hence, it is crucial to define goals, monitor the progress towards the goals and name activities to reach the goals for the learner (MR1). Following their theory of learner-centered design (LI2), Soloway et al. [39] named the concept of scaffolds with a specific goal, purpose and learning guidance as a central component of learning software when the purpose is to complete constructive activities such as writing empathetic texts (MR2). In his cognitive theory of multimedia learning, Mayer named the "multimedia principles" (LI3), which state that "people learn more deeply from words and pictures than from words alone" (p. 47, [40]). Therefore, to guide learners, the tool needs to incorporate both words and images to reduce the load for a single processing channel (MR3). Moreover, we 
Literature Issues and User Stories $\quad$ Meta- / User Requirements

\begin{tabular}{|c|c|}
\hline LI1 & $\begin{array}{c}\text { Feedback on skills } \\
\text { (Hattie and Timperley 2007) }\end{array}$ \\
\hline LI2 & $\begin{array}{l}\text { Learner-centered design } \\
\text { (Soloway 1994) }\end{array}$ \\
\hline $\mathrm{LI}_{3}$ & $\begin{array}{l}\text { Multimedia Principle } \\
\text { (Mayer 2009) }\end{array}$ \\
\hline $\mathrm{LI}_{4}$ & $\begin{array}{c}\text { Emotional and cognitive empathy } \\
\text { (Davis 1983) }\end{array}$ \\
\hline LI5 & $\begin{array}{l}\text { Learner control principle } \\
\text { (Scheiter and Gerjets 2007) }\end{array}$ \\
\hline US1 & $\begin{array}{c}\text { As a student, I would like to use an empathy lear- } \\
\text { ning tool that provides input based on scientific } \\
\text { theory in order to reliably use the tool. }\end{array}$ \\
\hline US2 & $\begin{array}{l}\text { As a student, I want an empathy learning tool to } \\
\text { be simple, convenient to use, with a clear and } \\
\text { functional design and accessible on any device. }\end{array}$ \\
\hline $\mathrm{US}_{3}$ & $\begin{array}{c}\begin{array}{c}\text { As a student, I would like to see the progress of } \\
\text { my current and past achievements in order to } \\
\text { follow the development of my empathy skills and } \\
\text { stay motivated. }\end{array} \\
\text {. }\end{array}$ \\
\hline $\mathrm{US}_{4}$ & $\begin{array}{l}\text { As a student, I would like to receive further } \\
\text { recommendations on how to be more empathetic, } \\
\text { for example, in the form of readings or videos, in } \\
\text { order to be able to improve myself gradually. }\end{array}$ \\
\hline $\mathrm{US}_{5}$ & $\begin{array}{c}\begin{array}{c}\text { As a student, I would like to improve my empathy } \\
\text { skills through practical experience, e.g., in the } \\
\text { form of multimedia role plays or task-based } \\
\text { learning scenarios. }\end{array} \\
\end{array}$ \\
\hline US6 & $\begin{array}{c}\text { As a student, I would like to receive feedback on } \\
\text { my empathy skill based on my personality and } \\
\text { the application context in order to ensure the } \\
\text { given feedback really helps me to improve. }\end{array}$ \\
\hline US7 & $\begin{array}{l}\text { As a student, I would like to practice my empathy } \\
\text { skills regularly with immediate and individual } \\
\text { feedback to improve my empathy self-awareness. }\end{array}$ \\
\hline US8 & $\begin{array}{c}\text { As a student, I would like to have the option to } \\
\text { compare myself with others, only when I would } \\
\text { like to, in order to assess how I perform in a pool } \\
\text { of similar people. }\end{array}$ \\
\hline
\end{tabular}

\begin{tabular}{|c|c|}
\hline MR1 & $\begin{array}{l}\text { Feedback by defining goals, monitoring progress } \\
\text { and naming activities to reach the goals. }\end{array}$ \\
\hline MR2 & $\begin{array}{l}\text { Scaffolds through orientation, goal and purpose } \\
\text { of learning context and learning task. }\end{array}$ \\
\hline $\mathrm{MR}_{3}$ & $\begin{array}{l}\text { Auditory and visual channels for processing } \\
\text { information. }\end{array}$ \\
\hline MR4 & $\begin{array}{l}\text { Emotional and cognitive theory-based empathy } \\
\text { learning. }\end{array}$ \\
\hline $\mathrm{MR}_{5}$ & Possibilities to control the learning input. \\
\hline UR1 & $\begin{array}{l}\text { Learning tool must be simple, intuitive and easy } \\
\text { to use with low setup costs and effort. }\end{array}$ \\
\hline UR2 & $\begin{array}{c}\text { Provide overview of students' learning } \\
\text { development. }\end{array}$ \\
\hline $\mathrm{UR}_{3}$ & $\begin{array}{l}\text { Provide overview of further learning material on } \\
\text { empathy skills, such as videos or readings. }\end{array}$ \\
\hline UR4 & $\begin{array}{l}\text { Embed the learning tool in a practical task-based } \\
\text { or role-playing pedagogical scenario. }\end{array}$ \\
\hline UR5 & $\begin{array}{l}\text { Feedback and recommendations based on } \\
\text { personality and application context. }\end{array}$ \\
\hline UR6 & $\begin{array}{l}\text { Learning tool with regular, instant and individual } \\
\text { empathy feedback. }\end{array}$ \\
\hline UR7 & $\begin{array}{l}\text { Comparisons illustrating other people's behavior } \\
\text { or skill level should be an option for users. }\end{array}$ \\
\hline
\end{tabular}

Design Principles

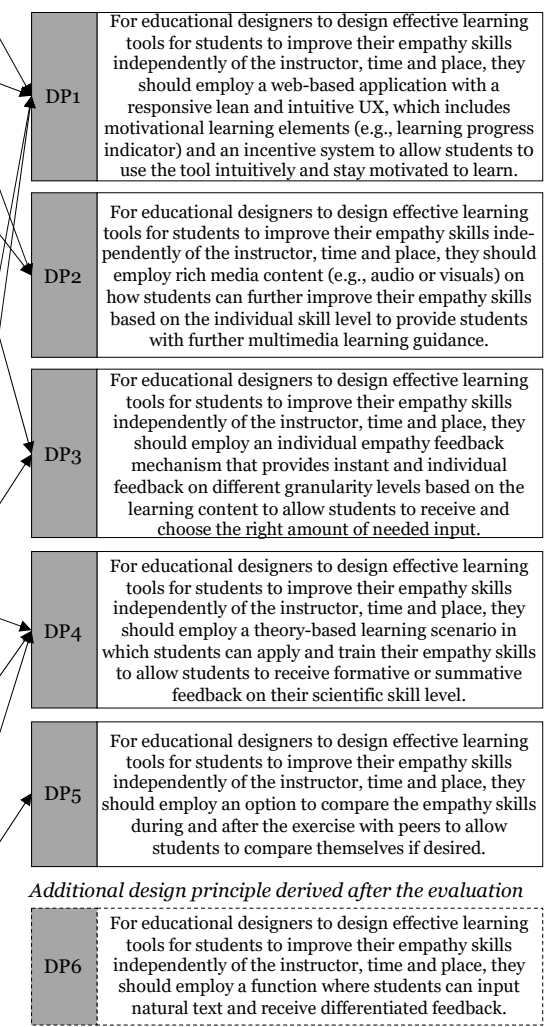

Figure 2. Overview of the derived design principles according to Gregor et al. [31]

follow the empathy construct of Davis (LI4), which guides our empathy learning tool with the structure of emotional and cognitive empathy tutoring (MR4) [2]. Lastly, the learners' control principle (LI5) is of special significance for learning skills, since it aims to enable learners to adjust the information needed for their personal learning process (MR5) [41].

\subsection{Deriving Requirements from Student Interviews}

Based on the derived LIs and MRs, we conducted 28 semi-structured interviews according to Gläser and Laudel [32]. The interview guideline consists of 30 questions and each interview lasted mean $=40.91$ minutes $(S D=15.9$ minutes $)$. The interviewees were a subset of students at our university who are all potential users of an empathy learning tool. The participants were asked about the following topics: experience with technology-based learning systems, importance of skills in university education, requirements for a system that supports learning metacognition skills (e.g., functionalities, design) and requirements for a system that supports learning empathy (e.g., functionalities, design). In order to gain impressions resulting from many years of learning experience, only master's students were recruited for the interviews. The interviewed students had a mean age of 24.82 years $(S D=1.98)$ and all students were studying economics, law or psychology; 15 were male, 13 were female. After a more precise transcription, the interviews were evaluated using a qualitative content analysis. The interviews were coded, and abstract categories were formed. The coding was performed using open coding to form a uniform coding system during evaluation [32]. Based on these results, we gathered 269 user stories (USs) and identified seven user requirements (URs) following [33].

\subsection{Deriving Design Principles and Design Features}

Based on our identified meta-requirements and user requirements, we established an initial set of design principles as shown in Figure 2. We instantiated the five initial DPs through ten design features (DF) in an initial version of our adaptive empathy learning tool (Table 1) guided by [34].

The first design principle (DP1) specifies that the artifact should be built as a web-based application with a responsive, lean and adaptive user interface, which includes motivational learning elements. Therefore, we instantiated a lean and adaptive learning process as well 

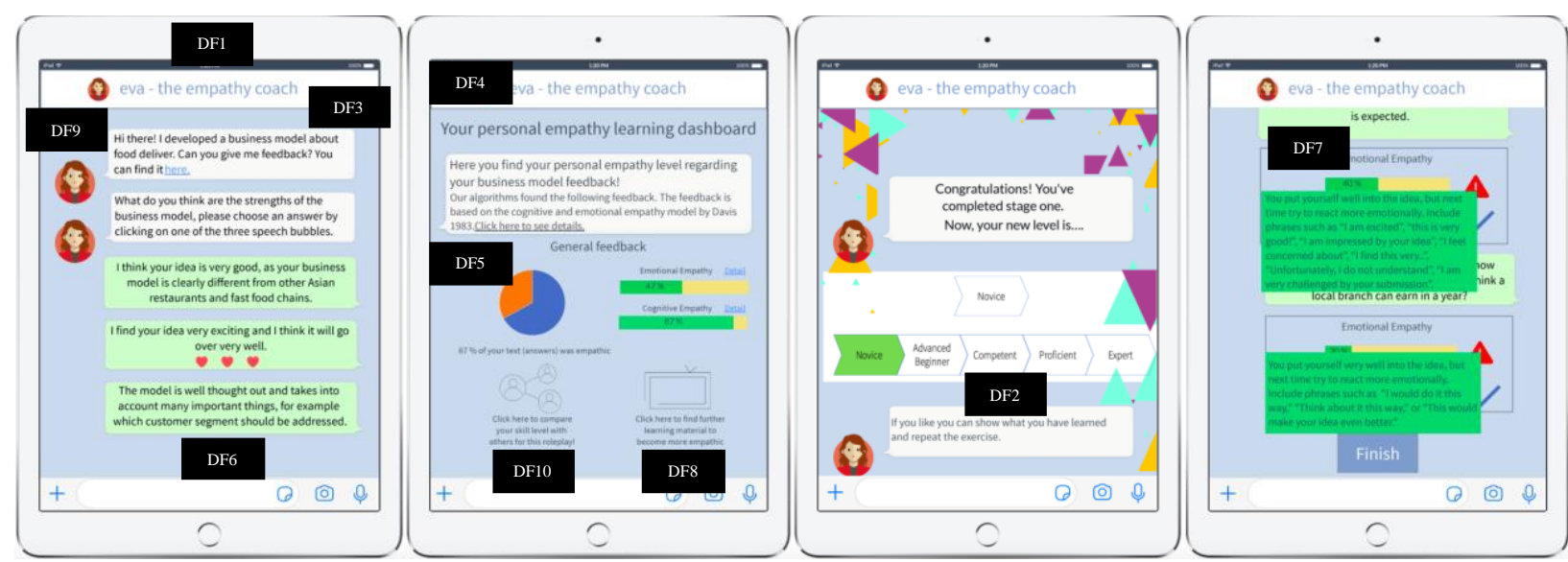

Figure 3. Screenshot of instantiated prototype $E v a$ with exemplary design features

as an intuitive learning experience with a conversational interface (DF1, DF3). In addition, the student is able to learn with an individual empathy learning dashboard, which provides an intuitive overview of the learning content and empathy theory, provides the empathy task feedback in different granularity levels and indicates further learning possibilities (e.g., comparison with other students) (DF4). The dashboard also guides the user to a progress bar that gives the student an overview of their learning progress to help her to stay motivated (DF2).

\begin{tabular}{|c|c|c|c|c|c|c|}
\hline \multicolumn{7}{|c|}{ Design Features of the Initial Implemented Design Principles } \\
\hline \multicolumn{2}{|c|}{$\begin{array}{l}\text { Design Features of the Initial } \\
\text { Version of } E v a\end{array}$} & \multirow{2}{*}{\begin{tabular}{|c|} 
DP1 \\
$X$
\end{tabular}} & \multirow{2}{*}{\begin{tabular}{|c|} 
DP2 \\
$X$
\end{tabular}} & \multirow{2}{*}{\begin{tabular}{|c|} 
DP3 \\
$X$
\end{tabular}} & \multirow[t]{2}{*}{ DP4 } & \multirow[t]{2}{*}{ DP5 } \\
\hline DF1 & $\begin{array}{l}\text { Web-based learning tool, } \\
\text { lean design, direct response }\end{array}$ & & & & & \\
\hline DF2 & $\begin{array}{l}\text { A progress bar which gives } \\
\text { the user an overview of his } \\
\text { learning progress }\end{array}$ & $\mathrm{X}$ & & & & \\
\hline DF3 & $\begin{array}{l}\text { Embedding in a pedagogical } \\
\text { conversational agent }\end{array}$ & $\mathrm{X}$ & & & & \\
\hline DF4 & $\begin{array}{l}\text { Individual empathy learning } \\
\text { dashboard }\end{array}$ & $\mathrm{X}$ & & & & \\
\hline DF5 & $\begin{array}{|lr|}\begin{array}{l}\text { Multifunctional } \\
\text { support (videos, }\end{array} & \text { learning } \\
\text { and diagrams) } & \end{array}$ & & $\mathrm{X}$ & $\mathrm{X}$ & & \\
\hline DF6 & $\begin{array}{l}\text { Answer options in the chat } \\
\text { process, through which the } \\
\text { user can train his empathy } \\
\text { skills and receive feedback }\end{array}$ & & & $\mathrm{X}$ & & \\
\hline DF7 & Direct/ individual feedback & & $\mathrm{X}$ & $\mathrm{X}$ & & \\
\hline DF8 & $\begin{array}{l}\text { Link to additional learning } \\
\text { materials }\end{array}$ & & & $X$ & & \\
\hline DF9 & \begin{tabular}{|l} 
Embed learning tool in \\
student peer reviews
\end{tabular} & & & & $\mathrm{X}$ & \\
\hline DF10 & \begin{tabular}{|l}
$\begin{array}{l}\text { Optional comparison with } \\
\text { other students }\end{array}$ \\
\end{tabular} & & & & & $X$ \\
\hline
\end{tabular}

Table 1. Instantiation of design principles with design features

DP4 describes the need for a theory-based learning scenario. Thus, we aimed to embed the empathy learning tool in a proven teaching learning scenario, which is easy to set up and domain-agnostic-applicable. Therefore, we used the concept of student peer reviews, since students

might be able to apply and train their empathy skills when giving feedback on a business model of a peer [42] (DF9). The potential of student peer feedbacks and metacognition skill training has been successfully shown for other skill training based on NLP such as argumentations skills [43]. DP5 includes the option for students to compare their individual empathy level with other students. Therefore, we implanted a learning progress bar as a learning path indicator (DF10), in which students might compare themselves with peers.

Next, DP2 requires rich media content (e.g., audio or visual material). Therefore, the empathy feedback is instantiated with several graphics and images to enable the student to easily receive learning information (DF5). DP3 highlights the need for individual feedback to learn skills such as empathy. Thus, students should receive feedback based on their learning tasks conducted before, e.g., based on chosen pre-defined answers in a conversation with a conversational agent (DF6). Moreover, we instantiated a direct and individual feedback mechanism to help students to train their empathy skills (DF7). To provide the students with further learning material, we built a mechanism where students had the possibility to access further learning material such as videos and literature to learn more about the different dimensions of empathy (DF8).

To instantiate and evaluate the design principles above, we created a mock-up-based prototype called Eva by using the tool marvel ${ }^{2}$. The prototype Eva (Figure 3) guides students through providing a peer review on another student's business model through a conversational interface and an empathy learning dashboard.

\subsection{Proof-of-Concept Evaluation}

In the demonstration and evaluation phase, we aimed to evaluate our design principle in the form of

2 marvelapp.com 
our instantiated prototype Eva. We followed an ex ante evaluation using an artificial evaluation setup as proposed by [35]. The purpose of the evaluation is to check whether the design principles are useful for learners, in order to incorporate any change requests. The design principles were specifically examined based on the criteria of usefulness and usability. Moreover, our aim was to compare the overall perceived level of enjoyment, since the level of enjoyment is proven to have a major influence on the adoption of IT tools [44] and learning success of students [45].

To do so, we designed an experiment in which participants were asked to provide a peer review based on a provided business model essay. Participants of the treatment group used our prototype Eva for providing a business model review to an imaginary peer (see Figure 3). After the review task, they received adaptive feedback on their cognitive and their emotional empathy level based on [2]. Participants of the control group were asked to provide the same review. However, they only received a general empathy feedback. Moreover, the treatment was not embedded in our learning tool Eva and designed according to our design principles.

\begin{tabular}{|l|c|c|c|}
\hline & n & Age & Gender \\
\hline $\begin{array}{l}\text { Treatment Group: } \\
\text { adaptive empathy } \\
\text { learning tool Eva }\end{array}$ & 25 & $\begin{array}{c}\text { Mean 25.12 } \\
\text { SD 2.78 }\end{array}$ & $\begin{array}{c}17 \text { male, } \\
8 \text { female }\end{array}$ \\
\hline $\begin{array}{l}\text { Control Group: general } \\
\text { empathy feedback }\end{array}$ & 40 & $\begin{array}{c}\text { Mean 26.15 } \\
\text { SD 3.99 }\end{array}$ & $\begin{array}{c}9 \text { male, } \\
31 \text { female }\end{array}$ \\
\hline
\end{tabular}

Table 2. Overview of experiment participants

We recruited 65 students through social networks and mailing lists to take part in our experiment. The participants received a randomized link to the experiment. We received 25 valid answers from participants in the treatment and 40 valid answer from participants in the control group. Participants of the treatment group had an average age of $25.12(\mathrm{SD}=2.78)$; 17 were male, 8 were female. In the control group, participants' average age was $26.15(\mathrm{SD}=3.99), 9$ were male, 31 were female. Participants took 4 to 35 minutes for the experiment (mean 12.8 minutes). It consisted of three main phases: 1) pretest phase, 2) treatment phase and 3) posttest phase. The pre- and post-phases were consistent for all participants. In the treatment phase, we manipulated the level of feedback participants received after providing a business model feedback.

1) Pretest phase: The experiment started with a presurvey with eight questions. Here, we tested two different constructs to assess whether the randomization resulted in randomized groups. First, we asked four items to test the personal innovativeness in the domain of information technology of the participants following [46]. Second, we tested the construct of feedback-seeking of individuals following [47]. Example items are: "It is important for me to receive feedback on my performance." or "I find feedback on my performance useful.". Both constructs were measured with a 1- to 5-point Likert scale (1: totally disagree to 5 : totally agree, with 3 being a neutral statement).

2) Treatment phase: In the treatment phase of the experiment, participants read an essay about a business model. After, they were asked to provide a business model review by choosing one of three pre-defined answer statements for 1) strengths, 2) weaknesses and 3) improvement suggestions (nine answer statements in total) of the business model read prior. After the review, participants received feedback on their empathy skill based on the chosen review statements. The treatment group used our prototype Eva with adaptive empathy feedback (feedback particularly based on the individually given business model review). Participants of the control group conducted the treatment phase in unipark, only receiving general empathy feedback (e.g., with general theory-based suggestions about cognitive empathy such as "If you want to give cognitively emphatic feedback, try to put yourself more in the other person's shoes."). The business model essay and the nine review statements were completely the same for all participants. We only manipulated the learning tool interaction and the adaptivity of the empathy feedback between both groups. We did not provide any introduction to any of the tools.

3) Posttest phase: In the post-survey, we measured perceived usefulness (PU), intention to use (ITU) and ease of use (PEOU) following the technology acceptance model of [48]. Example items for the three constructs are: "Imagine the tool was available in your next course, would you use it?", "The use of the tool enables me to provide more empathetic feedback." or "I would find the tool to be flexible to interact with". Moreover, we tested the perceived level of enjoyment (PLE) to capture the subjective learning perception of students following the items of [49] by giving the following statements: "The interaction with the learning tool was exciting" and "It is fun to interact with the learning tool". Additionally, we gave participants of the treatment group items addressing the instantiated design principles: For evaluating DP1, „The learning journey would give me an overview of my learning process and thus motivate me. "; for DP2, "I would find the information about learning empathy helpful."; for DP3, "I would find the possibility to compare my empathy level with others useful."; and for DP4 and DP5, "I assume that the learning tool would help me improve my ability to give empathically appropriate feedback." and "I assume that the learning tool would help me improve my ability to give emotionally empathically appropriate feedback." All answers were captured on a 1-to 5-point Likert scale (1: totally disagree to 5 : totally agree, with 3 being a neutral statement). Additionally, we asked three qualitative 
questions: "What did you particularly like about the use of the empathy tool?", "What else could be improved?" and "Do you have any other ideas?" to both groups. Finally, we captured the demographics. Moreover, we included two control questions in the survey to check for invalid answers.

\section{Results}

For data analysis, we performed a double-sided t test (Welch's $t$ test) to assess whether differences between both groups are statistically significant. In order to control for potential effects of interfering variables with our rather small sample size and to ensure that randomization was successful, we compared the differences in the means of the two constructs included in the pretest. For both constructs, personal innovativeness and feedback-seeking of individuals, we received $\mathrm{p}$ values larger than 0.05 between the treatment and the control group.

Our main objective was to compare the perceived level of enjoyment between both groups, since level of enjoyment significantly influences the adoption of IT tools and learning success of students [44], [45]. The results indicate that students who used our adaptive empathy learning tool perceived the interaction to be significantly more enjoyable compared to the treatment group (mean $T G=3.58, S D T G=0.99$; mean $C G=3.10$, $S D C G=0.81 ; t$ value $=2.125, p=0.0375)$. Moreover, we aimed to evaluate the concept of our design principles and of our empathy learning tool as suggested by [35]. Our evaluation confirmed that all DP are mostly positively perceived by the participants (see Table 3 ). The mean values for the DPs are promising when comparing the results to the midpoints of the scale. All results are better than the neutral value of 3 and all normalized values are equal or greater than 0.7 ).

\begin{tabular}{|c|c|c|c|c|c|c|c|}
\hline TG, $\mathrm{n}=25$ & DP1 & DP2 & DP3 & DP4/5 & ITU & PU & PEOU \\
\hline mean & 3.64 & 3.5 & 2.9 & 3.5 & 3.56 & 3.64 & 3.98 \\
\hline SD & 0.86 & 0.87 & 0.73 & 0.87 & 0.59 & 0.63 & 0.71 \\
\hline normalized & 0.72 & 0.7 & 0.58 & 0.7 & 0.71 & 0.72 & 0.79 \\
\hline
\end{tabular}

Table 3. Evaluation of design principles (DP1-5)

Moreover, the intention to use (ITU), the perceived usefulness (PU) and the perceived ease of use (PEOU) are in general positively perceived. The perceived usefulness for giving more empathetic peer feedback and the intention to use Eva as an empathy learning tool show promising results (see Table 3). A positive technology acceptance is especially important for learning tools to ensure students are perceiving the usage of the tool as helpful, useful and easy to interact with. This will foster motivation and engagement to use the application.

As described above, we also included open questions in our survey to receive the participants' opinions about the perception of the interaction of Eva to evaluate our
DF and DP further. The general attitude of the interaction with Eva was very positive. The evaluation seems to confirm that students would be willing to use a learning tool for empathy skills and would be motivated to work with it, e.g., they were "curious about the empathy feedback". Participants, however, emphasized that "the tool was easy to use. The fun factor was also there, and it was fun to write with the bot." (DP1, DF3), and they also expressed confidence in the tool and praised the theoretically well-founded background of the exercises (DP2). The direct and individual feedback and the resulting potential for improvement for the users were mentioned by many of the participants (DP3), e.g., "the tool obviously and objectively evaluates a skill that previously seemed subjective to me. This helps to improve oneself better and to recognize possible improvement potentials". The qualitative evaluation also revealed some suggestions for improvement. The participants asked for more pre-defined response options for the business model feedback. Many also mentioned that they would like to write the feedback themselves in natural text, e.g., "The tool could be integrated with many variations of answers or a function where I can provide feedback myself" (DF6)

Based on the evaluation results, the design principles DP1-DP5 were validated and a new design principle was derived. The new design principle (DP6) specifies that an empathy learning tool should allow students to enter their own natural text and receive differentiated feedback. This is based on several qualitative comments that more differentiated empathy feedback on self-written natural texts would significantly improve the usefulness of Eva. DP6 is shown in Figure 2 as an additional design principle.

\section{Discussion and Conclusion}

In this paper, we reported our DSR project for the development of design principles for an adaptive empathy learning tool that aims to support students to improve their ability on how to react to other students' perspectives with intelligent feedback on texts. We evaluated our five initial design principles in a formative and artificial setting [35] through our instantiated prototype Eva. The results suggest that students would enjoy an empathy learning tool based on our design principles as an additional support for teachers in conveying and themselves in learning better empathy skills in large-scale or distance learning scenarios. To the best of our knowledge, we are one of the first studies to provide evaluated design principles for the design of an empathy learning tool. Our DPs were formulated based on the analysis of current issues related to theories of learning and teaching 
metacognition skills and needs and requirements of users based on cognitive dissonance theory [14]. We argue that a learning tool for empathy skills (and possibly other metacognition skills) that instantiates our DPs should increase the motivation of students to learn how to apply certain skills, for example, learn how to appropriately react to another person's perspective and thus improve the learning outcome. For example, an empathy learning tool that provides instant and individual feedback and gives students the flexibility to control their learning input and provides further learning material should increase the students' motivation to resolve dissonance and therefore construct new knowledge. We believe that lecturers and educational institutions can use these design principles to create their own empathy learning tools to improve their individual pedagogical scenarios. A number of limitations have to be considered with respect to our study. First, we gathered requirements from a certain theoretical perspective and a specific user group. It might be possible that other areas of literature and user groups might have led to different results. Moreover, we were not yet able to fully implement our empathy learning tool Eva with a fully functional automatic feedback algorithm based on NLP and ML in the back end. Therefore, we call for future research on corpora and ML models to model the empathy structure of student written texts (similar to [50]). Moreover, we encourage future research to investigate the embedding of an empathy learning tool in a dialog-based interaction design (such as [51], [52]). We expect our overall research project to contribute a nascent design theory [53] to the artifact class of IT learning tools for metacognition skills and thus contribute to the OECD Learning framework 2030 towards a metacognition-skillbased education.

\section{References}

[1] OECD, "The Future of Education and Skills Education 2030." 2018.

[2] M. H. Davis, "Measuring individual differences in empathy: Evidence for a multidimensional approach.," J. Pers. Soc. Psychol.,pp. 113-126, 1983.

[3] J. Luca and P. Tarricone, "Does Emotional Intelligence Affect Successful Teamwork?," Proc. 18th Annu. Conf. Australas. Soc. Comput. Learn. Tert. Educ., no. December 2001, pp. 367-376, 2001.

[4] M. Poser and E. A. C. Bittner, "Hybrid Teamwork: Consideration of Teamwork Concepts to Reach Naturalistic Interaction between Humans and Conversational Agents," in WI2020, 2020.

[5] S. H. Konrath, E. H. O'Brien, and C. Hsing, "Changes in dispositional empathy in American college students over time: A meta-analysis," Personal. Soc. Psychol. Rev., pp. 180-198, 2011.

[6] B. Lok and A. E. Foster, "Can Virtual Humans Teach Empathy?," in Teaching Empathy in Healthcare, Springer International Publishing, 2019, pp. 143-163.
[7] J. E. Seaman, I. E. Allen, and J. Seaman, "Higher Education Reports - Babson Survey Research Group," 2018.

[8] J. Hattie and H. Timperley, "The Power of Feedback," Rev. Educ. Res., pp. 81-112, 2007.

[9] L. S. Vygotsky, Mind in society: The development of higher psychological processes. Harvard university press, 1980.

[10] K. E. Gerdes, E. A. Segal, K. F. Jackson, and J. L. Mullins, "Teaching empathy: A framework rooted in social cognitive neuroscience and social justice," J. Soc. Work Educ., vol. 47, pp. 109-131, 2011.

[11] B. S. Santos, M. C. Junior, and J. G. De Souza, “An Experimental Evaluation of the NeuroMessenger: A Collaborative Tool to Improve the Empathy of Text Interactions," Proc. - IEEE Symp. Comput.

Commun., vol. 2018-June, pp. 573-579, 2018.

[12] S. Buechel, A. Buffone, B. Slaff, L. Ungar, and J. Sedoc, "Modeling empathy and distress in reaction to news stories," Proc. EMNLP, pp. 4758-4765, 2018.

[13] K. Peffers, T. Tuunanen, M. A. Rothenberger, and S. Chatterjee, "A Design Science Research Methodology for Information Systems Research," Journal of Management Information Systems, vol. 24. Taylor \& Francis, Ltd., pp. 45-77, 2007.

[14] L. Festinger, "Cognitive Dissonance," Sci. Am., vol. 207, no. 4, pp. 93-106, Oct. 1962.

[15] A. R. Hevner, S. T. March, J. Park, and S. Ram, "Design Science in Information Systems Research," Des. Sci. IS Res. MIS Q., vol. 28, no. 1, p. 75, 2004.

[16] T. Wambsganss and R. Rietsche, "Towards designing an adaptive argumentation learning tool," in 40th International Conference on Information Systems, ICIS 2019, 2020.

[17] R. T. Peterson and Y. Limbu, "The convergence of mirroring and empathy: Communications training in business-to-business personal selling persuasion efforts," J. Business-to-bus. Mark., vol. 16, no. 3, pp. 193-219, Jul. 2009.

[18] J. vom Brocke, W. Maaß, P. Buxmann, A Maedche, J. M. Leimeister, and G. Pecht, "Future Work and Enterprise Systems," Bus. Inf. Syst. Eng., vol. 60, no. 4, pp. 357-366, 2018.

[19] J. Decety and P. L. Jackson, "The functional architecture of human empathy.," Behavioral and cognitive neuroscience reviews, pp. 71-100, 2004.

[20] E. J. Lawrence, P. Shaw, D. Baker, S. BaronCohen, and A. S. David, "Measuring empathy: Reliability and validity of the Empathy Quotient," Psychol. Med., vol. 34, pp. 911-919, Jul. 2004.

[21] R. N. Spreng, M. C. McKinnon, R. A. Mar, and B. Levine, "The Toronto empathy questionnaire: Scale development and initial validation of a factoranalytic solution to multiple empathy measures," $J$. Pers. Assess., vol. 91, no. 1, pp. 62-71, 2009.

[22] H. Bell, "Creative Interventions for Teaching Empathy in the Counseling Classroom," J. Creat. Ment. Heal., vol. 13, no. 1, pp. 106-120, Jan. 2018.

[23] M. Hen and M. Goroshit, "Emotional competencies in the education of mental health professionals," 
Soc. Work Educ., vol. 30, no. 7, pp. 811-829, Oct. 2011.

[24] J. N. Bailenson, N. Yee, J. Blascovich, A. C. Beall, N. Lundblad, and M. Jin, "The use of immersive virtual reality in the learning sciences: Digital transformations of teachers, students, and social context," Journal of the Learning Sciences, vol. 17, no. 1. pp. 102-141, 2008.

[25] S. Weis and H.-M. Süß, "Social Intelligence-A Review and CriticalDiscussion of Measurement Concepts," in Emotional intelligence.An international handbook, R. Schulze and R. D. Roberts, Eds. Hogrefe, 2005, pp. 203-230.

[26] D. R. Sadler, "Formative assessment and the design of instructional systems," Instr. Sci., vol. 18, no. 2, pp. 119-144, Jun. 1989.

[27] D. Kralicek, L. Von Rabenau, S. Shelar, and P. Blikstein, "Inside out:Teaching empathy and socialemotional skills," in IDC 2018 - Proceedings of the 2018 ACM Conference on Interaction Design and Children, 2018, pp. 525-528.

[28] H. Fromm, T. Wambsganss, and M. Söllner, "Towards a Taxonomy of Text Mining Features," in European Conference of Information Systems, 2019.

[29] T. Wambsganss, N. Molyndris, and M. Söllner, "Unlocking Transfer Learning in Argumentation Mining: A Domain-Independent Modelling Approach," in 15th International Conference on Wirtschaftsinformatik, 2020.

[30] A. J. Elliot and P. G. Devine, "On the motivational nature of cognitive dissonance: Dissonance as psychological discomfort.," J. Pers. Soc. Psychol., vol. 67, no. 3, pp. 382-394, 1994.

[31] J. Piaget, T. Brown, and K. J. Thampy, "The Equilibration of Cognitive Structures: The Central Problem of Intellectual Development. Jean Piaget , Terrance Brown , Kishore Julian Thampy," Am. J. Educ., vol. 94, no. 4, pp. 574-577, Aug. 1986.

[32] J. Gläser and G. Laudel, Experteninterviews und qualitative Inhaltsanalyse : als Instrumente rekonstruierender Untersuchungen. VS Verlag für Sozialwiss, 2010.

[33] M. Cohn, "User Stories Applied For Agile Software Development," 2004.

[34] S. Gregor, L. Chandra Kruse, and S. Seidel, "The Anatomy of a Design Principle," J. Assoc. Inf. Syst., vol. Forthcomin, 2020.

[35] J. Venable, J. Pries-Heje, and R. Baskerville, "FEDS: A Framework for Evaluation in Design Science Research,” Eur. J. Inf. Syst., vol. 25, pp. 77-89, 2016.

[36] K. Bauman and A. Tuzhilin, "Recommending Remedial Learning Materials to Students by Filling Their Knowledge Gaps," MIS Q., vol. 42, no. 1, pp. 313-332, 2018.

[37] H. M. Cooper, "Organizing knowledge syntheses: A taxonomy of literature reviews," Knowl. Soc., vol. 1, no. 1, pp. 104-126, 1988.

[38] J. vom Brocke, A. Simons, K. Riemer, B. Niehaves, R. Plattfaut, and A. Cleven, "Standing on the shoulders of giants: Challenges and recommendations of literature search in information systems research,"
Commun. Assoc. Inf. Syst., vol. 37, no. 1, pp. 205224, Aug. 2015.

[39] E. Soloway, M. Guzdial, and K. E. Hay, "LearnerCentered Design: The Challenge for HCI in the 21st Century," interactions, pp. 36-48, 1994.

[40] R. E. Mayer, Multimedia Learning. Cambridge: Cambridge University Press, 2009.

[41] K. Scheiter and P. Gerjets, "Learner control in hypermedia environments," Educ. Psychol. Rev., vol. 19, no. 3, pp. 285-307, 2007.

[42] R. Rietsche and M. Söllner, "Insights into Using IT-Based Peer Feedback to Practice the Students Providing Feedback Skill," Proc. 52nd Hawaii Int. Conf. Syst. Sci., 2019.

[43] T. Wambsganss, C. Niklaus, M. Cetto, M. Söllner, J. M. Leimeister, and S. Handschuh, "AL : An Adaptive Learning Support System for Argumentation Skills," in ACM CHI Conference on Human Factors in Computing Systems, 2020.

[44] M. K. O. Lee, C. M. K. Cheung, and Z. Chen, "Acceptance of Internet-based learning medium: The role of extrinsic and intrinsic motivation," Inf. Manag., vol. 42, no. 8, pp. 1095-1104, 2005.

[45] R. Pekrun and E. J. Stephens, "Academic emotions.," APA Educ. Psychol. handbook,Individ. Differ. Cult. Context. factors., pp. 3-31, 2012.

[46] R. Agarwal and E. Karahanna, "Time Flies When You're Having Fun: Cognitive Absorption and Beliefs about Information Technology Usage," MIS $Q$, vol. 24, no. 4, p. 665, Dec. 2000.

[47] S. J. Ashford, "Feedback-Seeking in Individual Adaptation: A Resource Perspective," Acad. Manag. J., vol. 29, no. 3, pp. 465-487, Sep. 1986.

[48] V. Venkatesh and H. Bala, "Technology acceptance model 3 and a research agenda on interventions," Decis. Sci., vol. 39, no. 2, pp. 273-315, May 2008.

[49] S. Kim, J. Lee, and G. Gweon, "Comparing data from chatbot and web surveys effects of platform and conversational style on survey response quality," Conf. Hum. Factors Comput. Syst. - Proc., pp. 1-12, 2019.

[50] T. Wambsganss, C. Niklaus, M. Söllner, S. Handschuh, and J. M. Leimeister, "A Corpus for Argumentative Writing Support in German," in 28th International Conference on Computational Linguistics (Coling), 2020.

[51] T. Wambsganss, M. Söllner, and J. M. Leimeister, "Design and Evaluation of an Adaptive DialogBased Tutoring System for Argumentation Skills," in International Conference on Information Systems (ICIS), 2020.

[52] T. Wambsganss, R. Winkler, P. Schmid, and M. Söllner, "Unleashing the Potential of Conversational Agents for Course Evaluations: Empirical Insights from a Comparison with Web Surveys," in Twenty-Eighth European Conference on Information Systems, 2020.

[53] S. Gregor and A. R. Hevner, "Positioning and Presenting Design Science Research for Maximum Impact," 2013. 